\title{
Дифрференцирующее действие растворителя при необменной сорбции аминокислот ионообменниками
}

\author{
Чепкина Е.Ф., Хохлова О.Н., Хохлов В.Ю. \\ ФГБОУ ВО «Воронежский государственный университет», Воронеж
}

Поступила в редакцию 23.05.2019 г.

DOI: https://doi.org/10.17308/sorpchrom.2019.19/784

При необменной сорбции ионообменниками веществ одной природы действующие силы являются одинаковыми, что осложняет разделение многокомпонентных смесей. Регулирование доминирующих взаимодействий в сорбционных системах с помощью изменения условий проведения процесса, позволит более эффективно разделять вещества без применения дополнительных электролитов. Известно, что растворитель играет важную роль во многих физико-химических процессах, особенно на границе раздела фаз, поэтому целью работы являлось выявление закономерностей необменной сорбции глицина и триптофана из водно-спиртовых растворов с различным соотношением компонентов в растворителе анионообменником AB-17-2П (Cl). В работе использована простейшая аминокислота, не имеющая бокового радикала (глицин) и самая гидрофобная аминокислота (триптофан), а также высокоосновный анионообменник AB-17-2П в Cl-форме, имеющий в качестве функциональных групп четвертичный азот. Исследованы свойства водно-спиртовых растворов аминокислот, анионообменника и равновесие необменной сорбции при различном содержании этилового спирта в составе растворителя $(0,25,40,50,60,75,100 \%$ по объему). Установлено, что свойства водноспиртовых растворов аминокислот (триптофана и глицина) и ионообменника $\mathrm{AB}-17-2 П(\mathrm{Cl})$ определяются соотношением воды и этилового спирта в составе растворителя, а также наличием полярных и гидрофобных частей в структуре объектов исследования. Изменение свойств сорбента и исследуемых сорбатов в зависимости от содержания органического компонента в растворе носит немонотонный характер: набухание анионообменника минимально при $75 \%$ alc, а растворимость триптофана имеет максимум при $40 \%$ alc, чего, однако, не наблюдается для глицина. Выявлено, что необменная сорбция аминокислот анионообменником АВ-17-2П из водно-спиртовых растворов также носит немонотонный характер в зависимости от содержания органического компонента в составе растворителя - наблюдается минимум сорбции триптофана и максимум сорбции глицина при сопоставимом содержании воды и спирта в составе растворителя. Различие в закономерностях сорбции исследуемых аминокислот определяется различием в их свойствах - полярностью глицина и гидрофобностью триптофана. Изменение состава растворителя позволяет регулировать сорбционные характеристики в системах анионообменник-аминокислота и более эффективно разделять смеси цвиттерлитов за счет дифференцирующего действия растворителя.

Ключевые слова: водно-спиртовый раствор, необменная сорбция, аминокислоты, анионообменник.

\section{The differentiating effect of solventat non- exchangeablesorption of amino acids ion exchangers}

\author{
Chepkina E.F., Khokhlova O.N., Khokhlov V.Yu. \\ Voronezh State University, Voronezh
}

At not exchange of non-exchange sorption of substances by ion exchangers of the same nature, the acting forces are the same, which complicates the separation of multicomponent mixtures. Regulation of do- 
minant interactions in sorption systems by changing the conditions of the process will allow more efficient separation of substances without the use of additional electrolytes. It's known that solvent plays an important role in many physical and chemical processes, especially on the phase boundary, therefore the purpose of work was identification of patterns of non-exchange sorption of glycine and tryptophan from hudroalcoholic solutions with different ratios of components in the solvent anion exchange AV-17-2P $(\mathrm{Cl})$.

We used the simplest amino acid, not having the side of the radical (glycine), and the hydrophobic amino acid (tryptophan) and the high basic anion exchanger AV-17-2P in the Cl-form, having as functional groups Quaternary nitrogen. The properties of hudroalcoholic solutions of amino acids, anion exchanger and the equilibrium of non-exchange sorption at different ethyl alcohol content in the solvent were investigated $(0,25,40,50,60,75,100 \%$ by volume $)$. It is established that the properties of hudroalcoholic solutions of amino acids (tryptophan and glycine) and ion exchanger AV-17-2P $(\mathrm{Cl})$ are determined by the ratio of water and ethyl alcohol in the solvent, as well as the presence of polar and hydrophobic parts in the structure of the objects of study.The change in the properties of the sorbent and the sorbates under study depending on the content of the organic component in the solution is nonmonotonic: the swelling of the anion exchanger is minimal at $75 \%$ alc, and the solubility of tryptophan is maximum at $40 \%$ alc, which, however, isn't observed for glycine. It is revealed, that non-exchange sorption of amino acids by anion exchangerAV-17-2P from hudroalcoholic solutions also is nonmonotonic, depending on the content of organic component in the composition of the solvent - is observed the min sorption of tryptophan and the maximum sorption of glycine with a comparable content of water and alcohol in the composition of the solvent.The difference in the patter of sorption of amino acids under study is determined by the difference in their properties - the polarity of glycine and tryptophan hydrophobicity. Changing the composition of the solvent allows you to adjust the sorption characteristics in the anion exchanger-amino acid systems and separate the mixtures of zwitterlites due to the differentiating action of the solvent.

Keywords: hudroalcoholic solution, non-exchange sorption, amino acids, anion exchanger.

\section{Введение}

Известно, что растворитель играет важную роль во многих физикохимических процессах, особенно на границе раздела фаз, например, при сорбционных равновесиях [1]. Это широко используется в хроматографии [2], и реже в процессах разделения и очистки веществ. Смена растворителя с водного на спиртовый, например, используется на заключительных стадиях получения аминокислот при их кристаллизации [3]. Необменная сорбция ряда цвиттерлитов на различных сорбентах из водно-спиртовых растворов исследована авторами в работах [4-6], однако представленные данные нельзя распространить на широкий круг сорбатов и сорбентов. Поэтому целью работы являлось выявление закономерностей необменной сорбции глицина и триптофана из водно-спиртовых растворов с различным соотношением компонентов в растворителе анионообменником АВ-17-2П (Cl).

\section{Эксперимент}

В работе использована простейшая аминокислота, не имеющая бокового радикала, - глицин и самая гидрофобная аминокислота - триптофан, а также высокоосновный анионообменник AB-17-2П в Cl-форме, имеющий в качестве функциональных групп четвертичный азот.

Исследованы свойства водно-спиртовых растворов аминокислот, анионообменника и равновесие необменной сорбции при различном содержании этилового спирта в составе растворителя $(0,25,40,50,60,75,100 \%$ по объему). Необменную сорбцию проводили в статических условиях методом переменных концентраций. Содержание аминокислот в сорбенте рассчитывали по разности концентраций в растворе до и после сорбции с учетом объема и массы контактирующих фаз. Анализ триптофана в равновесных растворах осуществляли спектрофотометрически [7], а глицина с использованием пьезоэлектрического сенсора [8], по градуировочным графикам, полученным предварительно для каждого состава растворителя. 


\section{Обсуждение результатов}

Смешанные водно-органические растворители характеризуются изменением структуры и физико-химических свойств в зависимости от состава, при этом некоторые закономерности имеют немонотонный характер [9]. Падение диэлектрической проницаемости и изменение сетки водородных связей водно-спиртовых растворов является важным при растворении сложных органических веществ, например, аминокислот. Это отражается на уменьшении растворимости цвиттерлитов в целом и особенностях ее изменения при увеличении содержания спирта.

Так для триптофана характерен максимум растворимости при $40 \%$ органического компонента по массе [10]. Поскольку у этой аминокислоты есть полярная амино-карбоксильная группировка и гидрофобный боковой радикал, влияние спирта в составе растворителя неоднозначно. При введении незначительных количеств органического компонента растворимость аминокислоты увеличивается за счет снижения полярности среды и ее способности образовывать раствор гидрофобных частиц. Однако при нарастании концентрации спирта большую роль играет тот факт, что его молекулы разрушают водородные связи между молекулами гидратной воды полярной амино-карбоксильной группировки аминокислоты и растворимость триптофана падает.

Для полярного глицина такого эффекта не наблюдается, и его растворимость уменьшается за счет падения диэлектрической проницаемости при нарастании содержания спирта в составе растворителя [10]. Двойственность природы анионообменника (наличие гидрофобной матрицы и полярных функциональных групп с противоионами) определяет набухание сорбента в водно-спиртовых растворах (рис.1).

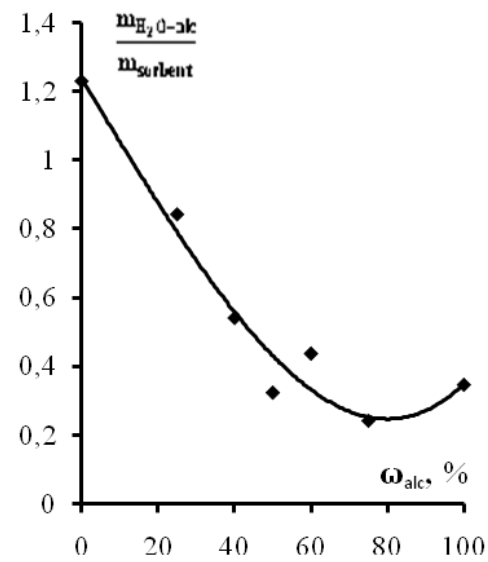

Рис. 1. Набухаемость анионообменника АВ-17-2П (Cl-)

в водно-спиртовых растворах

Как видно из рис. 1, минимальное набухание анионообменника в водноспиртовых растворах наблюдается при содержании в растворителе $75 \%$ спирта по объему. При увеличении содержания органического компонента полярные взаимодействия в гидратных оболочках функциональных групп и противоионов ослабевают, в то время как усиливаются гидрофобные взаимодействия с участием радикала. Полученные данные согласуются с литературными [11], относящимися, однако, к узкому диапазону изменения содержания спирта.

Таким образом, свойства водно-спиртовых растворов аминокислот (триптофана и глицина) и ионообменника $\mathrm{AB}-17-2 П(\mathrm{Cl})$ определяются соотношением воды 
и этилового спирта в составе растворителя, а также наличием полярных и гидрофобных частей в структуре объектов исследования.

Свойства сорбатов и сорбента в водно-спиртовых растворах определяют механизм и величину сорбции. Изотермы поглощения триптофана из растворов на основе смешанного растворителя представленные на рис. 2.
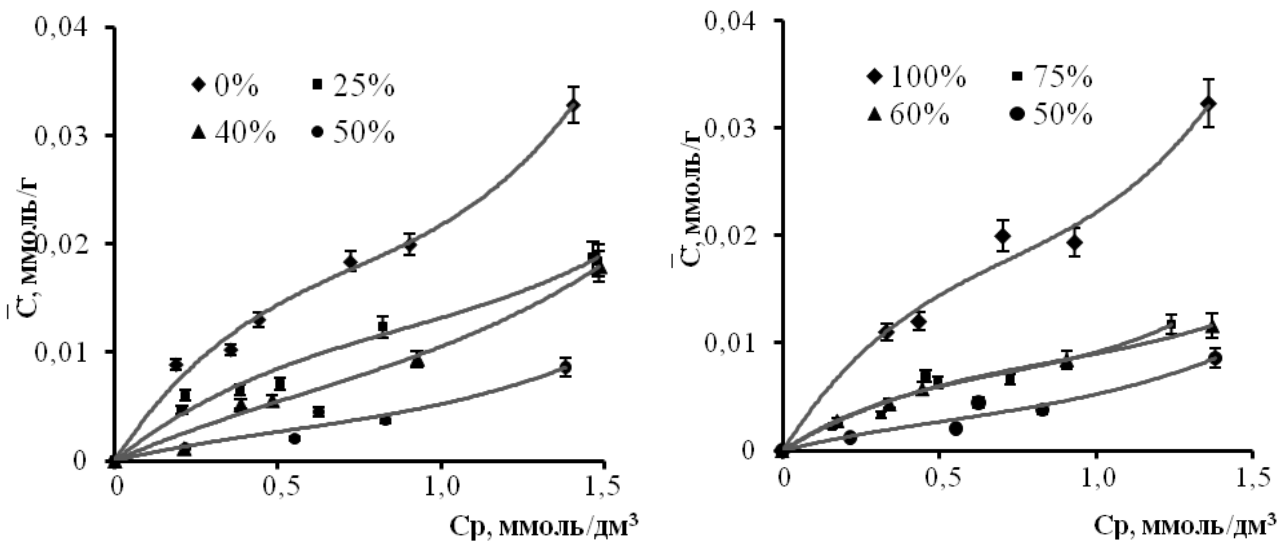

а 6

Рис. 2. Изотермы сорбции триптофана анионообменником АВ-17-2П

в Cl-форме из водно-спиртовых растворов: $\mathrm{a}-\omega_{\mathrm{alc}}=0-50 \% ; \sigma-\omega_{\mathrm{alc}}=50-100 \%$

Они имеют идентичный вид, что свидетельствует о том, что механизм сорбции, заключающийся в полярных взаимодействиях амино-карбоксильной группировки с противоионами хлора и гидрофобных взаимодействий радикала аминокислоты с элементами матрицы [12], не изменяется. Однако количество поглощенного триптофана из чистых (вода, этиловый спирт) и смешанных (водно-спиртовых) растворов неодинаково и в зависимости от соотношения компонентов в растворителе имеет немонотонный характер с минимумом, соответствующим содержанию $50 \%$ спирта по объему.

Это связанно с изменением характеристик внешнего и формирующегося внутреннего раствора в фазе сорбента. Поскольку при необменной сорбции веществ ионообменниками одним из определяющих факторов, влияющих на величину сорбции, является содержание растворителя в фазе сорбента для формирования внутреннего раствора [1], то минимум при набухании ионита в водно-спиртовом растворе обуславливает минимальную сорбцию триптофана в этой системе.

Для выявления роли бокового радикала при необменной сорбции аминокислот исследована сорбция глицина анионообменником АВ-17-2П в Cl-форме из водно-спиртовых растворов. Сорбция этой аминокислоты выше, чем поглощение триптофана в идентичных условиях в силу того, что глицин меньше по размеру, легче преодолевает границу раздела фаз и встраивается в систему водородных связей в сорбенте. При этом основным механизмом закрепления являются ион-дипольные взаимодействия с противоионом хлора и образование водородных связей [12]. На рис. 3 показана зависимость величины сорбции этой аминокислоты от содержания спирта в растворителе при различных концентрациях глицина. Как видно из рисунка, увеличение содержания этилового спирта в растворе до соотношения компонентов 1:1 приводит к незначительному росту сорбции простейшей аминокислоты, что связано с более легким встраиванием глицина в разрыхленную сетку водородных связей в водно-спиртовом растворе. При содержании спирта, превышающем концентрацию воды в растворителе, сорбция простейшей аминокислоты резко падает. Это 
вызвано тем, что превалирующим фактором становится ослабевание полярных взаимодействий с уменьшением диэлектрической проницаемости среды.

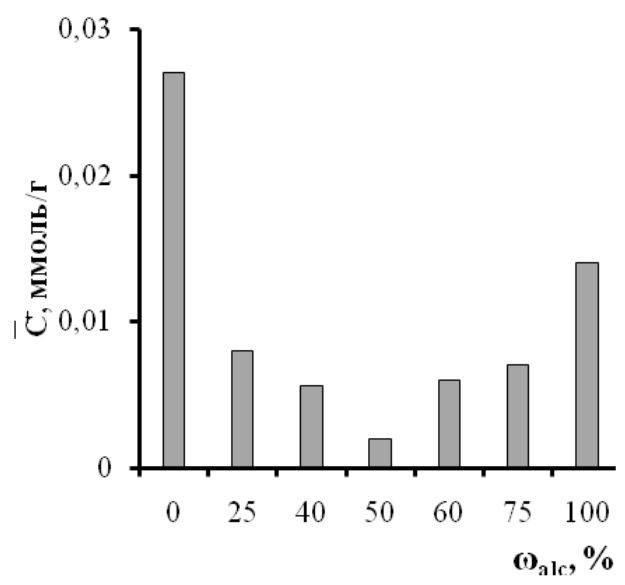

Рис. 3. Зависимость содержания триптофана в анионообменнике при сорбции из растворов с различным содержанием спирта $\left(\mathrm{C}_{\text {равн }}=0.5\right.$ ммоль/дм $\left.{ }^{3}\right)$

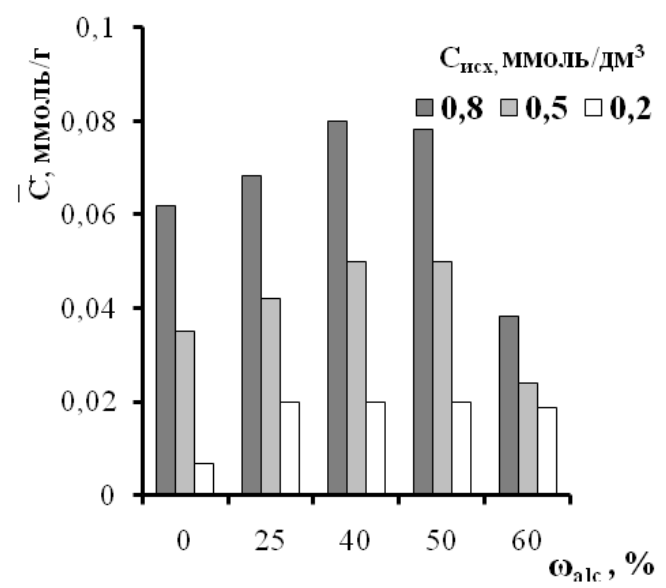

Рис. 4. Зависимость необменной сорбции глицина анионообменником AB-17-2П (Cl) от содержания этилового спирта в составе растворителя.

Таким образом, изменение состава растворителя по-разному влияет на сорбцию глицина и триптофана. На рис. 5 на примере системы с соотношением воды и спирта 1:1 показан дифференцирующий эффект растворителя - при изменении полярности лучше сорбирующийся глицин поглощается лучше, а для хуже сорбирующегося триптофана сорбция уменьшается.

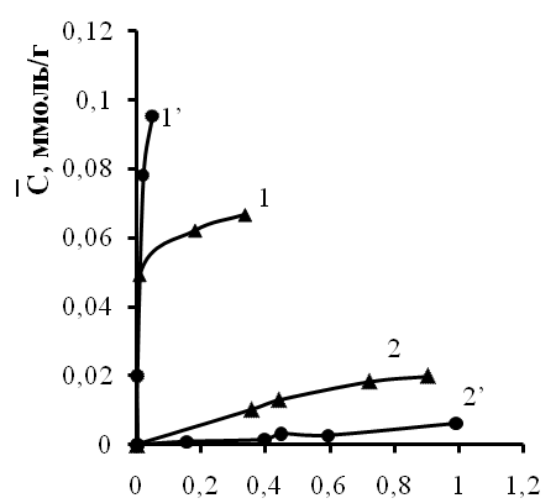

Ср, ммоль $/$ дм$^{3}$

Рис. 5. Дифференцирующее действие растворителя при необменной сорбции глицина (1 и 1') и триптофана (2 и 2') анионообменником АВ-17-2П $(\mathrm{Cl})$ в водном (1 и 2) и водно-спиртовом (50\%) растворе (1'и 2')

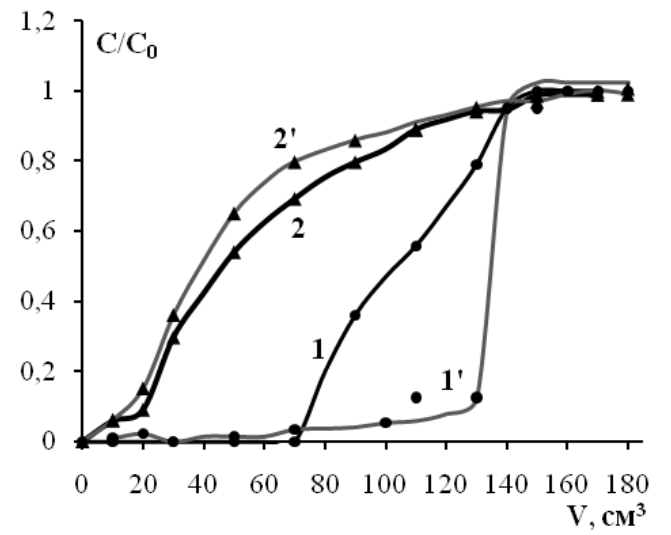

Рис. 6. Выходные кривые необменной сорбции глицина (1 и 1') и триптофана (2 и 2') анионообменником $\mathrm{AB}-17-2 П(\mathrm{Cl})$ из водного (1 и 2) и водноспиртового (50\%) раствора (1'и 2')

Использование дифференцирующего действия растворителя на стадии сорбции при разделении аминокислот позволит проводить процесс более эффективно, что является актуальным, поскольку невысокие и близкие по значению величины сорбции сходных по строению веществ существенно осложняют разделение их смесей в условиях необменного поглощения. 
Для разделения смеси исследуемых аминокислот (глицина и триптофана С0АК=0.001 моль/дм ${ }^{3}$ ) при использовании водного и смешанного растворителя раствор со скоростью $1.5 \mathrm{~cm}^{3} /$ мин пропускали через слой анионообменника АВ-17-2П в Cl-форме (высота слоя 1.5 см, диаметр - 3.7 см). Выходные кривые сорбции представлены на рисунке 6.

Из рис. 6 видно, что, как и в равновесных условиях, триптофан сорбируется хуже, чем глицин. При этом введение спирта в состав растворителя оказывает большее воздействие на поглощение простейшей аминокислоты - его сорбция улучшается, объем раствора, из которого удаляется глицин, возрастает с 70 до $130 \mathrm{~cm}^{3}$, при этом фронт сорбции обостряется. Таким образом, эффективность разделения аминокислот увеличивается.

\section{Заключение}

Таким образом, установлено, что свойства водно-спиртовых растворов аминокислот (триптофана и глицина) и ионообменника $\mathrm{AB}-17-2 П(\mathrm{Cl})$ определяются соотношением воды и этилового спирта в составе растворителя, а также наличием полярных и гидрофобных частей в структуре объектов исследования. Выявлено, что необменная сорбция триптофана и глицина анионообменником АВ-17-2П из водноспиртовых растворов носит немонотонный характер в зависимости от содержания органического компонента в составе растворителя. Изменение соотношения компонентов в растворителе позволяет регулировать сорбционные характеристики в системах анионообменник-аминокислота и разделять смеси цвиттерлитов за счет дифференцирующего действия растворителя.

\section{Список литературы}

1. Гельферих Ф. Иониты. Москва. Иностранная литература. 1962.490 с.

2. Долгоносова А.М., О.Б. Рудаков, И.С. Суровцев. Колоночная аналитическая хроматография как объект математического моделирования. ГЕОХИ РАН. Воронеж. 2013. 400 c.

3. Гринштейн Дж. Химия аминокислот и пептидов. М. Мир. 1966. 413 с.

4. Капуцкий Ф.Н., Юркштович Т.А., Борщевская Т.Н. // Журнал физической химии. 1995. Т. 69. № 9. С. 1673-1676.

5. Капуцкий Ф.Н., Старобинец Г.Л., Юркштович Т.А. // Доклады АН БССР. 1991. Т. 35. № 9. C. 805-809.

6. Старобинец Г.Л., Капуцкий Ф.Н., Борщенская Т.И. // Доклады АН Беларуси. 1994. Т. 38. № 2. С. 63-65

\section{References}

1. Gel'ferih F. Ionity. M., Inostrannaja literature, $1962,490 \mathrm{p}$.

2. Dolgonosova A.M., Rudakov O.B., Surovcev I.S. Kolonochnaja analiticheskaja hromato-
7. КотоваД.Л.Спектрофотометрическое определение аминокислот, витаминов и антибиотиков. Воронеж. Научная книга. 2013. $81 \mathrm{c}$.

8. Зяблов А.Н., Моничева Т.С., Селеменев В.Ф. // Журнал Аналитика и контроль. 2012. Т. 16. № 4. С. 406-409.

9. Стабников В.Н., И.М. Ройтер, Т.Б. Процюк. Этиловый спирт. М. Пищевая промышленность. 1976. 273 с.

10. Bowden N.A., Johan P.M. Sanders, Marieke E. // Journal of Chemical \& Engineering. 2018. Vol. 63. pp. 488-497

11.Рудаков О.Б., Кудухова И.Г. // Сорбичонные и хроматографические прочессы. 2011. T.11. № 6. C. 880-886.

12.Трунаева Е.С., Хохлова О.Н., Хохлов В.Ю. // Сорбиионные и хроматографические проиессы. 2018. Т. 18. № 2. С. 142-149.

grafija kak object matematicheskogo modelirovanija, GEOHI RAN, Voronezh, 2013, 400 p. 3. Grinshtejn Dzh., Khimija aminokislot I peptidov, M., Mir, 1966, 413 p. 
4. Kapuckij F.N., Jurkshtovich T.A., Borshhevskaja T.N., J. of Physical Chemistry, 1995, Vol. 69, No 9, pp. 1673-1676.

5. Kapuckij F.N., Starobinec G.L., Jurkshtovich T.A., Doklady AN BSSR, 1991, Vol. 35, No 9, pp. 805-809.

6. Starobinec G.L., Kapuckij F.N., Borshhenskaja T.I., Doklady AN Belarusi, 1994, Vol. 38, No 2, pp. 63-65.

7. Kotova D.L. Spektrofotometricheskoe opredelenie aminokislot, vitaminov I antibiotikov, Voronezh, Nauchnaja kniga, 2013, 81 p.

8. Zyablov A.N., Monicheva T.S., Selemenev V.F., J. of Analitical Control., 2012, Vol. 16, No 4, pp. 406-409.

Хохлова Оксана Николаевна - доцент кафедры аналитической химии, к.х.н., Воронежский Государственный Университет, Воронеж

Хохлов Владимир Юрьевич - профессор кафедры аналитической химии, д.х.н., Воронежский Государственный Университет, Воронеж

Чепкина Елизавета Федоровна - студент кафедры аналитическая химия, Воронежский Государственный Университет, Воронеж
9. Stabnikov V.N., Rojter I.M., Procjuk T.B.. Etilovyj spirt. M., Pishhevaja promyshlennost', 1976, 273 p.

10. Nathan A. Bowden, Johan P.M. Sanders, Marieke E., Journal of Chemical \& Engineering. 2018, No 63, pp. 488-497. DOI: Available at:researchgate.net (accessed 21.01.2019)

11.Rydakov O.B., Kudukhova I.G., J. of Sorbtive and Chromatographic processes, 2011, Vol. 11, No 6, pp. 880-886.

12.Trunaeva E.S., Khokhlova O.N., Khokhlov V.Yu., J. of Sorbtive and Chromatographic processes, 2018, Vol. 18, No 2, pp. 142-149.

Khokhlova Oksana N. - associate professor, department of analytical chemistry, Voronezh State University, Voronezh, e-mail: okxox@yandex.ru

Khohlov Vladimir Yu. - Professor, department of analytical chemistry, Voronezh State University, Voronezh, e-mail: vladkh70@mail.ru

Chepkina Elizaveta F. - student, department of analytical chemistry, Voronezh State University, Voronezh, e-mail: lizachepkina12@gmail.com 